\title{
The hydro-geotechnical decision cycle - having mine design and planning decisions made by the right people
}

\author{
J.W. Hall RPS Aquaterra, Australia
}

\begin{abstract}
The design of pit slopes where groundwater or pore pressure has some influence on slope stability requires two key mining disciplines to be applied; geotechnical engineering and hydrogeology. These two broad disciplines also cover structural geology, geomechanical, groundwater and hydro-mechanical coupled modelling and surface water hydrology. These are all specialist disciplines with specific education and training requirements. With experience, we develop an understanding of, and can even become experts in, these other disciplines. That is, we become adept practitioners in the overall slope design and mine planning process. However, this takes time.
\end{abstract}

What of our site based mine planning staff, who are mostly young and still developing their overall mine planning skills? It is not uncommon for our site based geotechnical engineer (or hydrogeologist) to have a whole range of duties assigned to them, many of which are outside their current skill and experience levels. Is this fair? Can it result in practical, cost effective or safe slope designs? It can, but only when our site staff are provided with adequate technical support from the cross disciplines.

So, what does this support look like, and when do we need to provide it? A useful way to assess this is to consider what I call the Hydro-Geotechnical Decision Cycle. This is simple process whereby the geotechnical engineers does what they are good at (and qualified to do) and the hydrogeologists do the same, so that together they can develop the appropriate mine planning solutions through an iterative process of data collection, analysis, design, implementation and feedback. Sound familiar? This is the same as a Continuous Improvement cycle (i.e. plan-do-check-act).

This paper develops the concept of the Hydro-Geotechnical Decision Cycle and presents examples of where it can help when applied and where it has gone wrong when it has not been applied.

\section{Introduction}

When mining below the water table, and particularly in deep pits, groundwater levels and pore pressures can have significant influence on pit slope stability. The design of pit slopes where this is the case requires the application of two key technical disciplines; geotechnical engineering and hydrogeology, although these two broad disciplines cover a broad range of skills including structural geology, geomechanics, groundwater and hydro-mechanical coupled modelling, and surface water hydrology. These are all specialist disciplines with specific educational and training requirements. With experience, geotechnical engineers and hydrogeologists develop a good understanding of, and can even become experts in, these other disciplines. That is, they become adept practioners in the overall slope design and mine planning process.

However, gaining this level of skill and experience takes time. What of our site based mine planning staff, many of who are still developing their overall mine planning skills? It is not uncommon for the site based geotechnical engineer (or hydrogeologist) to have a whole range of duties assigned to them, many of which are outside their current skill and experience levels. This can lead to less than optimal site decisions being made which can have implications for practical, cost effective and/or safe slope designs. These pitfalls can be avoided, if and when our site staff are provided with the appropriate technical support from the cross disciplines. 
So, what does this support look like, and when do we need to provide it? A useful way to assess what support is required and when to apply it, is to consider what I call the Hydro-Geotechnical Decision Cycle. This is a simple process whereby the geotechnical engineers do what they are good at (and qualified to do) and the hydrogeologists do the same, so that together they can develop the appropriate mine planning solutions through an iterative process of data collection, analysis, design, implementation and feedback. This may sound familiar: it is essentially the same as the standard continuous improvement cycle process (i.e. plan-do-check-act) adopted by most successful businesses.

While it is called the Hydro-Geotechnical Decision Cycle, it can be similarly applied to the integrated technical relationship between others in the overall mine planning and design process and mine operations.

The paper is brief, as the concept is not rocket science, but mostly common sense. The paper and the 'typical examples' presented are designed to provide high level understanding of how things can go right, and wrong, rather than detailed analysis. The concept and examples are best demonstrated by simple graphics and photographs of specific examples, which will be shown in the formal conference presentation.

\section{The Hydro-Geotechnical Decision Cycle}

The Hydro-Geotechnical Decision Cycle process can be illustrated by the simple continuous improvement cycle shown in Figure 1. As with any iterative decision making process, there are also a number of feedback loops within the overall cycle.

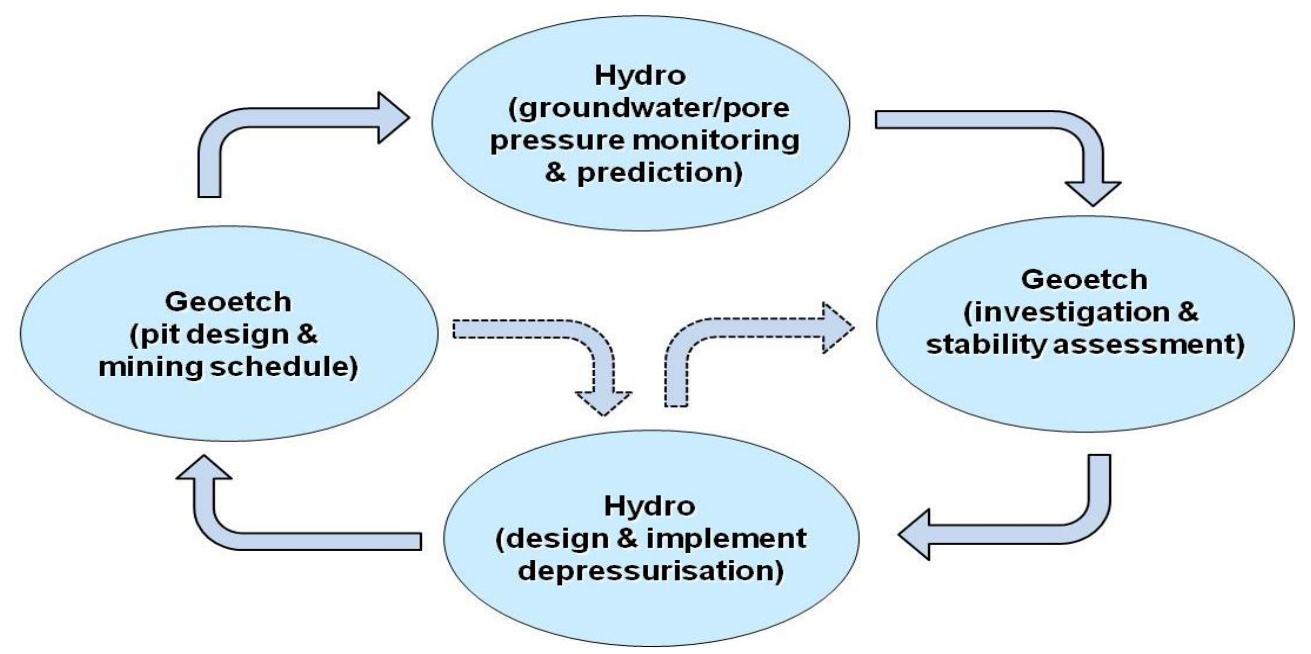

Figure 1 Hydro-Geotechnical Decision Cycle

In a bit more detail, the process (using a slope depressurisation case as an example) could involve the following specific steps and processes:

Hydrogeological:

- Investigate to determine ambient groundwater and pore pressure conditions.

- Predict natural groundwater and pore pressure responses over life of mine (based on preliminary pit design and schedule).

- Provide details to the geotechnical engineer.

Geotechnical:

- Determine pit wall geotechnical conditions and assess slope stability issues.

- Assess groundwater and pore pressure implications on pit slope stability and mine design.

- Determine whether depressurisation is required to meet slope design criteria. 
- Provide broad depressurisation requirements to the hydrogeologist.

Hydrogeological:

- Assess depressurisation options and designs.

- Predict performance (pore pressure reduction).

- Feedback to geotechnical engineer (feedback loop to stability assessment step).

Geotechnical:

- Assess whether predicted depressurisation is sufficient to meet slope stability criteria.

- If, not assess whether shortfalls can be designed out.

- Feedback to hydrogeologist.

Hydrogeological:

- Re-assess depressurisation design and predicted performance (if required).

- Provide revised design of depressurisation system and/or confirmation of realistic achievable depressurisation performance to the geotechnical engineer.

Geotechnical:

- Design pit slope and develop mine plan around achievable depressurisation.

- Identify key locations for pore pressure monitoring to provide adequate slope stability monitoring.

- Provide details to hydrogeologist.

Hydrogeological:

- Install pore pressure monitoring facilities (piezometers, bores etc.) in target locations.

- Review monitoring data and compare with design (i.e. validate predictions).

- Recalibrate prediction models as required and revise forward predictions as required.

- Provide performance data and revised predictions to geotechnical engineer.

Geotechnical:

- Assess whether actual depressurisation performance (or revised predictions of future performance) is sufficient.

- Feedback to hydrogeologist whether additional depressurisation is required.

Hydrogeological:

- Assess whether additional depressurisation is possible.

- Feedback to geotechnical engineer on revised achievable depressurisation.

Geotechnical:

- Revise slope design, if required, and so on.

The cycle would then continue over the life of mine. As a cycle, the process can start at any step and often does, especially where a new owner acquires an existing operating mine (or re-opens an old mine) where there has only been limited, if any, hydro-geotechnical work completed to date. For a new operation starting up, the logical steps to start are the initial hydrogeological or geotechnical steps listed above. 
The above example covers pit slope design issues related to pit slope depressurisation. A similar process would be involved where dewatering or even surface water management was the issue.

\section{How it can work well}

When appropriately adopted, the geotechnical engineers and mine planners can get on with their pit slope and mine designs secure in the knowledge that they are working with appropriate data and realistic predictions of likely depressurisation (or other water management performance). Adoption of the Hydro-Geotechnical Decision Cycle process also provides the opportunity for the geotechnical engineer and mine planner to have a reality check on the water management consequences of mine planning decisions, before they are implemented.

Typical examples of mines where The Hydro-Geotechnical Decision Cycle process has worked well are those mines where it was clearly recognised well ahead of mining that depressurisation (or dewatering, or surface water management) would be critical factors and where the need for an integrated Hydro-Geotechnical approach was identified and committed to during feasibility studies and carried through to mine operations. An obvious indication of when the process is working well is when the mine manager can readily explain the planned depressurisation or dewatering system and how the system works. This may seem obvious, but there are many instances where this is not the case.

\section{What happens when it doesn't work}

We can learn a lot more from looking at where the process has not worked so well, as the consequences of getting it wrong become (unfortunately) more obvious and spectacular. The single 'examples' presented below cover a small selection of where things have not gone so well and cover a variety of cases where the appropriate level of interaction within mine planning teams and between mine planning and mine operations staff, as well as simply between geotechnical engineers and hydrogeologists. Additional examples will be presented at the conference.

\subsection{Hydrogeological-geotechnical interaction}

The mine (a deep iron ore mine in Western Australia) had an onsite based hydrogeologist, but due to staff turnover, no site based geotechnical engineers. Following a partial pit wall failure, the hydrogeologist was instructed to 'depressurise that pit wall'. However, no geotechnical information was provided on likely pit wall failure mechanisms or depressurisation targets (dewatering or pore pressure reduction required). The result was, that a very large number of closely spaced and deep (long) horizontal drain holes were drilled. It was later concluded that that the programme implemented far exceeded what was actually required. In this example, the pit wall did not fail (which was a great outcome), but the depressurisation measures implemented cost much more than was really required.

The key learning here is: Provide all the relevant information to the hydrogeologists so that they can design a fit for purpose depressurisation system.

\subsection{Pit slope management-mine water management interaction}

The mine (a deep copper-gold mine in New South Wales) had spent considerable resources on depressurising a very high pit wall, characterised by numerous faults and joint systems which were sub-parallel to the pit wall. As part of the overall mine water management system, a surface water interception dam was required at the pit crest above this pit wall which, sensibly, was designed and initially operated with a semi-automated pumping system to keep the dam dry. However, after a particularly lengthy dry period, the pumping system was removed to be use elsewhere at the mine. During the next winter season (with normal rainfall) the dam filled and the pit wall was partially re-saturated. Luckily, there were only some minor, bench scale failures induced by this re-saturation, but it could have been much worse. 
The key learning here is: Operate water management systems as designed, and talk to the geotechnical engineer about the potential consequences of modifying the system.

\subsection{Pit slope management - dewatering management interaction}

The mine (a deep industrial and gem stone mine in Western Australia) required a major transfer pumping station for the pit sump dewatering system about half way up the pit. The initial scheme involved steel transfer tanks but was enlarged to include an unlined open pond excavated into 'soft' ground above a slope that been actively dewatered/depressurised in the past to improve slope stability. Piezometer data showed significant fluctuations in pore pressures within the slope as the open pond filled and emptied, with the consequent increased risk of slope failure.

The key learning here is: Include the geotechnical engineer/hydrogeologist in the dewatering management planning process and avoid re-wetting previously dewatered/depressurised slopes.

\subsection{Pit slope management - mine management interaction}

This example is typical of many mines the world over, where there are no site based geotechnical engineers or hydrogeologists. The mine manager (or company CFO) observes that most of the depressurisation drain holes in a pit wall make very little (if any obvious water) and mistakenly conclude that the drilling programme to date has been a waste of time. They cancel future drilling without consulting the off-site geotechnical engineer or hydrogeologist, who could have pointed out that piezometric data show that the drains have achieved their purpose and have helped stabilise a slope. In some cases, this has led to subsequent slope failure.

The key learning here is: Let the experts (geotechnical engineer or hydrogeologist) analyse performance.

\subsection{Pit slope management - surface water management interaction}

At the time, there was no site based geotechnical engineer hydrogeologist at this mine (a deep gold mine in Tanzania). A dam had been constructed upstream of the main pit to control surface water flows and to provide a mine water storage. A large flow capacity diversion channel was constructed around the pit to convey any spillway discharge rapidly past a section of pit developed through a thick sequence of alluvium/colluvium to reduce the potential for the re-wetting this soft and unstable material. During a prolonged dry period, when the dam did not spill, the diversion channel had become constricted by rill material and weeds. In the next wet year, when the dam did spill, water was retained in the diversion channel (trapped by the rill/weeds) for some time. Infiltration of this water through the diversion channel base re-wet the previously dewatered alluvium/colluvium and resulted in a moderate scale failure. This required the end-tipping of waste rock to stabilise the slope and resulted in the sterilisation of some ore.

The key learnings here are: Maintain surface water management systems as designed and include assessment of the implications of general mine water management schemes in geotechnical and hydrogeological reviews by company technical services or consultants.

\section{Conclusions}

The concept of the Hydro-Geotechnical Decision Cycle is simple. It is a process whereby geotechnical, hydrogeological and other mine planning staff do what they are good at (and qualified to do) get input and feedback from the other site based and off-site experts as required. It also includes mine operations staff being made fully aware of the key objectives of pit slope (and mine dewatering) management programmes and system and mine operations staff consulting with the geotechnical engineers and/or hydrogeoloists before implementing mine design changes that might impact on the pit slope (and mine dewatering) management systems.

As outlined in the introduction, the concept is not rocket science, but mostly common sense. The 'typical examples' presented are designed to provide high level understanding of how the process can work and 
how things can go wrong when it doesn't. The concept and examples are best demonstrated by simple graphics and photographs of specific examples, and these will be presented at the conference. 
Hydrogeology 